\title{
Sistem Kenaikan Pangkat dan Kepuasan Kerja : Satu Kajian Kes Ke atas Perkhidmatan Awam Persekutuan Di Malaysia
}

\author{
Mohammad Chin*, Syed Azizi Wafa Syed Khalid Wafa, Ramraini Ali Hassan \\ Fakuliti Perniagaan, Ekonomi dan Perakaunan, Universiti Malaysia Sabah, Kota Kinabalu, Sabah \\ *Corresponding author: DB1511013T@student.ums.edu.my
}

\begin{abstract}
This research is a case study exploring the relationship between the promotion system and job satisfaction among federal civil servants in federal departments and agencies in Malaysia. The samples involved in this study are government officers serving in federal departments and agencies in the state of Sabah, Malaysia. A quantitative method was used in this study. A total of 700 questionnaires were distributed among federal civil servants in grades 41 to grades 54. A total of 420 questionnaires were returned but after screening only 380 questionnaires were found useable and analysed in the study. Questionnaires were distributed to respondents based on purposive sampling methods. A significant positive relationship was found between the promotion system and job satisfaction. This study will contribute knowledge through the empirical data obtained as well as gaining a better understanding of the relationship between the promotion system and the level of job satisfaction among federal public servants in Malaysia. From a practical perspective, the findings of this study can be used by policy makers, managers and researchers who are interested in improving the policy of human resource management within the public sector in Malaysia.
\end{abstract}

Keyword: Promotion system, job satisfaction, federal public service

\begin{abstract}
Abstrak
Kajian ini merupakan kajian kes meneroka hubungan di antara sistem kenaikan pangkat dengan kepuasan kerja di kalangan penjawat awam persekutuan di jabatan dan agensi persekutuan di Malaysia. Sampel kajian yang terlibat di dalam kajian ini berkhidmat di jabatan dan agensi persekutuan di negeri Sabah. Kaedah kuantitatif telah digunakan sepenuhnya di dalam kajian kes ini. Sebanyak 700 borang soalan kaji selidik telah diedarkan di kalangan penjawat awam persekutuan terdiri dari gred 41 hingga gred 54. Sebanyak 420 borang soal selidik telah dikembalikan namun 380 borang kaji selidik yang telah dijawap dengan sempurna dan digunakan untuk analisis dalam kajian. Edaran borang soalan kaji selidik kepada kesemua responden menggunakan kaedah persampelan purposive. Hasil kajian ini mendapati terdapat hubungan positif yang signifikan di antara sistem kenaikan pangkat dengan kepuasan kerja. Kajian ini akan menyumbang pengetahuan melalui bukti empirikal yang diperolehi daripada kajian ini dan seterusnya pemahaman yang lebih baik mengenai hubungan di antara sistem kenaikan pangkat dan tahap kepuasan kerja di kalangan pejawat awam persekutuan di Malaysia. Dari segi perspektif praktikal, hasil daripada kajian ini dapat digunakan oleh pembuat dasar, pengurus dan penyelidik pada masa akan datang yang berminat untuk membuat penambahbaikan dasar pengurusan sumber manusia di sektor awam Malaysia.
\end{abstract}

Kata Kunci: Sistem kenaikan pangkat, kepuasan kerja, perkhidmatan awam persekutuan.

(C) 2018 Penerbit UTM Press. All rights reserved

\subsection{PENGENALAN}

Menurut Maimunah (2009), sistem kenaikan pangkat merupakan salah satu aktiviti terpenting di dalam Pengurusan Sumber Manusia (PSM). Kajian ini bermula dengan satu kenyataan akhbar yang dikeluarkan oleh Yang Berbahagia Ketua Setiausaha Negara di akhbar Sinar Harian, (30 April 2013). Kenaikan Pangkat untuk skim-skim perkhidmatan tertentu di dalam perkhidmatan awam persekutuan begitu perlahan. Oleh yang demikian, kajian ini dilaksanakan untuk mengkaji isu yang dikemukakan sendiri oleh Ketua Setiausaha Negara, adakah perlaksanaan sistem kenaikan pangkat di dalam perkhidmatan awam persekutuan di Malaysia adil, perlahan dan seterusnya menjejaskan tahap kepuasan kerja di kalangan penjawat awam persekutuan di Malaysia. Persekitaran PSM pada masa kini semakin dinamik. Amalan dan dasar PSM perlu berubah bersesuaian dengan persekitaran PSM yang semakian mencabar pada masa kini. Pekerja merupakan aset paling bernilai kepada organisasi. Objektif, visi dan misi penubuhan organisasi hanya akan tercapai dengan bantuan para pekerja. Sistem kenaikan pangkat merupakan satu fungsi penting di dalam PSM yang perlu dilaksanakan organisasi bagi menghargai pekerja yang telah menujukkan prestasi yang baik semasa berkhidmat di dalam organisasi semasa. Organisasi di sektor awam tidak terkecuali bagi mempastikan setiap dasar dan amalan PSM yang diamalkan khususnya di dalam perlaksanaan sistem kenaikan pangkat bersesuaian dengan persekitaran PSM yang semakin mencabar pada masa kini. Para sarjana ekonomi menyatakan bahawa sistem kenaikan pangkat mempunyai dua tujuan utama yang khusus (Bakker, George, Jensen dan Murphy, 1988). Pertama, sistem kenaikan pangkat merupakan kaedah untuk memilih individu yang berkemampuan untuk memikul tanggungjawab yang lebih besar, dan kedua, sistem kenaikan pangkat boleh memotivasi pekerja untuk berusaha dengan lebih gigih di dalam organisasi (Lazear dan Rosen, 1981). Sementara itu, Heery dan Noon (2001) pula, mentakrifkan sistem kenaikan pangkat adalah pergerakan kedudukan pekerja di dalam hierarki organisasi. Kebiasanya pergerakan ini membawa kepada peningkatan dalam tanggungjawab dan status serta pakej saraan dan gaji yang 
lebih baik. Oleh yang demikian kesimpulannya, kenaikan pangkat merupakan satu peningkatan jawatan daripada jawatan rendah ke jawatan yang lebih tinggi yang diberikan kepada pekerja di dalam organisasi semasa.

Peluang kenaikan pangkat yang disediakan organisasi akan memberi kesan terhadap kepuasan kerja (Larwood, 1984; Landy, 1989). Pernyataan ini dipersetujui oleh kajian yang dilaksanakan oleh Weng, McElroy dan Morrow (2010) ke atas 176 buah organisasi di China terdiri daripada responden pengurus, profesional dan pekerjaan perkeranian. Kajian tersebut bersetuju sistem kenaikan pangkat memberi kesan terhadap tahap kepuasan kerja di kalangan pekerja di dalam organisasi. Weng et. all (2010), membahagikan sistem kenaikan pangkat terbahagi kepada dua iaitu keadilan sistem kenaikan pangkat dan kelajuan kenaikan pangkat.

Keadilan sistem kenaikan pangkat merujuk kepada persepsi penilaian pihak pekerja terhadap proses kenaikan pangkat yang dilaksanakan oleh organisasi, sama ada sistem kenaikan pangkat itu dilaksanakan secara adil atau sebaliknya (Erdrogan, Liden dan Kraimer, 2006). Persepsi pekerja dalam konteks ini bermaksud proses kenaikan pangkat perlu dilaksanakan melalui prosedur dan peraturan yang ditetapkan oleh organisasi (Sweeney dan McFarlin, 1993; Aryee, Budhwar dan Chen 2002;Choi, 2011) tanpa ada unsur bias ataupun berat sebelah.

Manakala, kelajuan kenaikan pangkat pula ditakrifkan oleh Dries, Pepermans dan De Kerpel (2008) sebagai peningkatan dari jawatan rendah ke jawatan yang lebih tinggi dalam satu tempoh masa perkhidmatan. Kelajuan kenaikan pangkat di dalam organisasi dilihat memberi sumbangan kepada kejayaan organisasi. Ini adalah disebabkan kelajuan kenaikan pangkat dapat menghasilkan pekerja yang lebih mudah berpuas hati dengan kerjanya dan membangunkan semangat pemilikan bersama di dalam organisasi (Salamin dan Hom 2005; Weng et. all, 2010).

Kepuasan kerja pula berkait rapat dengan emosi dan perasaan pekerja terhadap pekerjaan mereka (Locke, 1969). Kepuasan kerja telah tercapai apabila seseorang pekerja itu menyukai pekerjaan mereka (Spector, 1997). Kenaikan pangkat merupakan satu pengiktirafan ke atas usaha yang ditunjukkan pekerja semasa berkhidmat di dalam organisasi. Kajian Herzberg (2003) ke atas responden di kalangan penyelia, profesional dan pentadbir di Amerika Syarikat menemui pemberian pengiktirafan dan ganjaran yang diberikan ke atas pencapaian pekerja berupa kenaikan pangkat akan meningkatkan kepuasan kerja.

Kajian ini akan menggunakan teori pertukaran sosial untuk menyokong kajian ini untuk dilaksanakan. Teori pertukaran sosial dalam konteks sosiologi boleh dikesan melalui kajian yang dilaksanakan oleh Blau (1964), teori ini dibina berdasarkan teori Gouldner. Teori pertukaran sosial menjelaskan mengenai norma timbal balik yang adil di antara dua belah pihak. Sekiranya satu pihak telah memperolehi manfaat di dalam rangkaian hubungan sosial, satu pihak bertanggungjawab untuk membalasnya secara adil mengikut tempoh masa yang sesuai (Blau, 1964). Blau (1964) mencadangkan bahawa manfaat pertukaran yang dimaksudkan di dalam teori ini adalah manfaat pengiktirafan, status dan prestij. Dalam konteks kajian ini, pemberian kenaikan pangkat oleh organisasi merupakan manfaat sebagai pengiktirafan terhadap prestasi kerja memuaskan yang telah ditunjukkan oleh pekerja. Kajian yang dilaksanakan oleh Kuvaas (2003) ke atas pekerja industri perabot di Norway dan kajian Rosen, Slater, Chang dan Johnson (2013) ke atas pekerja sambilan dan sepenuh masa di sebuah universiti di Amerika Syarikat serta kajian oleh Wu dan Chaturvedi (2009) ke atas pekerja pengeluaran dan perkhidmatan industri di China, Singapura dan Taiwan mendapati teori pertukaran sosial telah digunakan untuk kajian kesan dasar dan amalan PSM ke atas sikap pekerja di dalam organisasi. Kajian-kajian ini mendapati kesan dasar dan amalan PSM ini dapat diselesaikan melalui keadilan pemberian ganjaran dalam tempoh masa yang sesuai.

Dengan mengambil kira penemuan ini, dijangkakan terdapat hubungan yang signifikan di antara sistem kenaikan pangkat dan kepuasan kerja. Kajian ini sangat sesuai untuk dilaksanakan bagi menyelidik sama ada sistem kenaikan pangkat yang dilaksanakan di dalam perkhidmatan awam sekarang benar-benar memuaskan hati para pekerja disektor awam atau sebaliknya. Kajian ini juga diharapkan dapat membantu kerajaan untuk menentukan strategi kaedah sistem kenaikan pangkat yang paling sesuai untuk meningkatkan kepuasan kerja di kalangan penjawat awam di Malaysia. Hasil kajian ini juga diharapkan memberi manfaat, rujukan data dan maklumat kajian untuk penyelidik lain pada masa hadapan dalam membuat usaha yang signifikan dan kajian selanjutnya isu isu sistem kenaikan pangkat dan kepuasan kerja di sektor awam Malaysia.

\subsection{Persoalan Kajian}

Kajian ini akan mengemukakan persoalan kajian yang utama seperti berikut:

a. Apakah terdapat hubungan di antara sistem kenaikan pangkat dengan kepuasan kerja di sektor awam Malaysia?

\subsection{Objektif Kajian}

Objektif kajian ini adalah seperti berikut:

a. Menganalisis hubungan di antara sistem kenaikan pangkat dengan kepuasan kerja perkhidmatan awam di Malaysia.

\subsection{Hipotesis}

Hipotesis 1: Terdapat perhubungan yang signifikan di antara sistem kenaikan pangkat dan kepuasan kerja perkhidmatan awam di Malaysia.

H1a: Terdapat perhubungan yang signifikan di antara keadilan sistem kenaikan pangkat dan kepuasan kerja.

H1b: Terdapat perhubungan yang signifikan di antara kelajuan kenaikan pangkat dan kepuasan kerja.

\subsection{TINJAUAN LITERATUR}

Pembolehubah bebas kajian ini adalah sistem kenaikan pangkat. Weng et. all (2010) dan Spector, (1997) menyatakan bahawa sistem kenaikan pangkat mempunyai hubungan yang signifikan dengan kepuasan kerja. Kajian mereka ini disahkan oleh kajian selanjutnya yang dilakukan oleh Ch'ng, Chong dan Nakesvari (2010), kajian ini telah dilaksanakan ke atas pensyarah universiti di Pulau Pinang. Hasil kajian mereka mendapati sistem kenaikan pangkat mempunyai hubungan yang signifikan dengan kepuasan kerja. Sekiranya peluang 
kenaikan pangkat terhad di dalam organisasi semasa, responden bersedia untuk meninggalkan organisasi lain, sekiranya terdapat peluang tawaran lain oleh organisasi luar. Ini membuktikan sistem kenaikan pangkat merupakan satu keperluan dalam peningkatan kerjaya individu di dalam organisasi. Organisasi seharusnya menyediakan laluan dan peluang kenaikan pangkat yang adil dan menarik untuk meningkatkan kepuasan kerja. Kenyataan ini dipersetujui oleh kajian yang yang dijalankan oleh Drafke dan Kossen's (2002) yang turut sama bersetuju kepuasan kerja akan meningkat apabila pekerja mendapati prospek kerjaya mereka pada masa depan di dalam organisasi menjadi lebih baik dan menarik.

\section{Keadilan Sistem Kenaikan Pangkat}

Keadilan sistem kenaikan pangkat merupakan sub konstruk pertama di bawah pembolehubah bebas sistem kenaikan pangkat untuk kajian ini. Perlaksanaan sistem kenaikan pangkat hendaklah dilaksanakan dengan adil mengikut prosidur dan tatacara yang telah ditetapkan oleh organisasi. Keadilan di dalam sistem kenaikan pangkat yang dijalankan secara telus dan tidak pilih kasih mempunyai hubungan yang signifikan dengan kepuasan kerja (Erdogan et. all, 2006). Kenyataan ini disokong oleh kajian yang dilaksanakan oleh Folger dan Konovsky (1989) terhadap responden di kalangan pekerja syarikat di Amerika Syarikat yang mendapati keadilan di dalam pemberian kenaikan pangkat kepada pekerja akan meningkatkan kepuasan kerja. Pekerja akan sentiasa menilai polisi sistem kenaikan pangkat yang dilaksanakan oleh organisasi. Pekerja akan membuat perbandingan perlaksanaan pemberian kenaikan pangkat ini dengan rakan sekerja di dalam organisasi dan di luar organisasi. Kenyataan ini disokong oleh kajian-kajian lepas yang mendapati pekerja amat mengharapkan dan berpuas hati sekiranya organisasi telah bertindak secara adil dan saksama selaras dengan tatacara, polisi dan prosidur perlaksanaan sistem kenaikan pangkat (Sweeney dan McFarlin, 1993; Aryee et. all, 2002).

Konsep keadilan pemberian kenaikan pangkat ini juga sejajar dengan pandangan di dalam teori pertukaran sosial. Di dalam teori ini konsep keadilan di dalam pemberian ganjaran dan pengiktirafan memberi kesan langsung terhadap pekerja. Ini disebabkan pekerja cenderung untuk membandingkan pemberian kenaikan pangkat di kalangan mereka di dalam organisasi. Perbandingan kebiasannya termasuklah kelayakan akademik, tempoh perkhidmatan dan senioriti yang sama di dalam organisasi. Perbandingan ini juga dilakukan ke atas rakan-rakan mereka di luar organisasi. Kenyataan ini dibuktikan oleh satu hasil kajian yang diperolehi oleh Burnett, Williamson dan Bartol (2009) yang dilaksanakan ke atas graduan dari Mid-Atlantik Universiti. Responden kajian terdiri daripada mereka yang diambil sebelum dan selepas ditawarkan pekerjaan. Responden kajian telah menyatakan bahawa mereka akan berpuas hati dengan kerja mereka selagi perlaksanaan sistem dan polisi kenaikan pangkat itu dilaksanakan dengan adil mengikut prosidur dan peraturan yang ditetapkan oleh organisasi walaupun majikan tidak mampu untuk menyediakan bayaran saraan dan gaji yang tinggi kepada mereka.

Di Malaysia agensi pusat yang bertanggungjawab untuk menentukan dasar dan amalan PSM adalah Jabatan Perkhidmatan Awam (Seketariat Komanwel, 2004). Perkhidmatan awam persekutuan di Malaysia telah menetapkan dasar, polisi dan struktur kenaikan pangkat untuk semua penjawat awam termaktub di dalam Peraturan Perlantikan, Kenaikan Pangkat dan Penamatan Perkhidmatan 2005 [P.U. (A) 176/2005] (Jabatan Perkhidmatan Awam, 2015). Peraturan ini merupakan rujukan utama di dalam perlaksanaan pemberian kenaikan pangkat untuk penjawat awam persekutuan di Malaysia. Selain daripada itu, Jabatan Perkhidmatan Awam juga telah mengeluarkan satu pekeliling khusus, pekeliling Perkhidmatan Bilangan 7 Tahun 2010 bagi Panduan Pengurusan Pemangkuan dan Kenaikan Pangkat untuk Pegawai Perkhidmatan Awam Persekutuan di bawah Sistem Saraan Baru (SSM) bagi memperincikan urusan kenaikan pangkat untuk penjawat awam persekutuan di Malaysia. Kandungan dasar dan polisi sistem kenaikan pangkat perkhidmatan awam persektuan di Malaysia adalah seperti berikut:
a. Kenaikan pangkat berdasarkan merit
b. Kenaikan pangkat diperakui oleh Ketua Perkhidmatan, Lembaga Kenaikan Pangkat akan menilai individu berkenaan berdasarkan perkara-perkara berikut:-
i. $\quad$ Pegawai, seorang yang efisyen dan berprestasi
ii. Pegawai, mempunyai kelayakan, pengetahuan, kemahiran dan pengalaman
iii. Pegawai, mempunyai personaliti yang sesuai untuk jawatan kenaikan pangkat, berintegriti dan berpotensi
iv. $\quad$ Pegawai, aktif di dalam aktiviti luar dan dalam organisasi.
c. Sebagai maklumat tambahan, sub-peraturan (ii) Lembaga Kenaikan Pangkat boleh mempertimbangkan aspek-aspek lain yang difikir sesuai di dalam keputusan kenaikan pangkat seorang pegawai.
d. Sub-peraturan (i) jika sekiranya terdapat lebih daripada seorang pegawai yang layak untuk dipertimbangkan kenaikan pangkat, kelayakan akademik, pengalaman berkerja dan senioriti seseorang pegawai akan diberi pertimbangan di dalam proses membuat keputusan kenaikan pangkat.

Syarat-syarat tambahan polisi kenaikan pangkat di dalam perkhidmatan awam persekutuan adalah seperti berikut:
a. Pegawai bebas daripada tindakan tatatertib.
b. Pegawai telah mengisytiharkan harta.
c. Pegawai telah lulus tapisan keutuhan Suruhanjaya Pencegahan Rasuah Malaysia (SPRM).
d. Pegawai bebas daripada senarai peminjam tegar institusi pinjaman pendidikan.

\section{Kelajuan Kenaikan Pangkat}

Sub konstruk kedua di bawah pembolehubah bebas sistem kenaikan pangkat di dalam kajian ini adalah kelajuan kenaikan pangkat. Kelajuan kenaikan pangkat merupakan peningkatan jawatan ke jawatan yang lebih tinggi untuk satu tempoh perkhidmatan (Dries et. all, 2008). Pertimbangan pemberian kenaikan pangkat kepada pekerja dinilai berdasarkan beberapa faktor seperti tempoh perkhidmatan, tahap pekerjaan, fungsi pekerjaan dan gred gaji (Weng et. all, 2010). Berdasarkan kajian-kajian lepas, dimensi tempoh merupakan faktor terpenting dalam kelajuan kenaikan pangkat. Sebagai contoh seseorang dinaikkan pangkat daripada jawatan semasa ke jawatan yang lebih 
tinggi setelah berkhidmat di dalam organisasi selama lima tahun. Ini bermakna kelajuan kenaikan pekerja itu adalah lima tahun. Pemberian kenaikan pangkat melibatkan peningkatan fungsi dan tahap pekerjaan dan gred gaji yang baru.

Kelajuan kenaikan pangkat di dalam organisasi dilihat memberi sumbangan kepada kejayaan organisasi. Ini adalah disebabkan kelajuan kenaikan pangkat dapat menghasilkan pekerja yang lebih mudah berpuas hati dengan kerjanya dan membangunkan semangat pemilikan bersama di dalam organisasi (Salamin dan Hom 2005; Weng et. all, 2010). Selain dari itu, organisasi juga dapat mengekalkan pekerja yang berbakat, berpengalaman dan berkemahiran untuk terus berkhidmat dengan organisasi semasa (Weng et. all, 2010). Hasil kajian yang dijalankan oleh Salamin dan Hom (2005) di sebuah bank di Switzerland mendapati kedudukan hierarki di dalam pekerjaan memberi makna terhadap pekerja di dalam organisasi. Pekerja menggangap pencapaian kerjaya yang menaik merupakan tanda pencapaian kerjaya yang bermakna bagi mereka (Salamin dan Hom, 2005). Ini bermakna pemberian kenaikan pangkat akan meningkatkan motivasi dan kepuasan kerja. Ini dibuktikan oleh satu kajian yang dijalankan oleh Danish dan Usman (2010) ke atas pekerja di peringkat pertengahan di dalam sektor awam dan swasta di Pakistan menunjukkan bahawa peluang kenaikan pangkat meningkatkan motivasi dan kepuasan kerja. Kenyataan ini disokong oleh kajian yang dijalankan oleh Weng et. all (2010) yang bersetuju bahawa peningkatan dalam kelajuan kenaikan pangkat dapat memberi kesan positif terhadap tahap kepuasan kerja. Kelajuan kenaikan pangkat selaras dengan norma timbal balik yang terdapat di dalam teori pertukaran sosial. Apabila pekerja telah menunjukkan prestasi kerja dengan baik seharusnya pekerja dibalas dengan pemberian pengiktirafan berupa kenaikan pangkat dalam tempoh yang ditetapkan.

Kajian yang dilaksanakan O'Donell dan Shelids (2002) ke atas penjawat awam persekutuan di Australia mendapati kelajuan kenaikan pangkat mempunyai hubungan yang signifikan dengan kepuasan kerja. Pernyataan ini disokong dengan penemuan hasil kajian yang dilaksanakan oleh Aminudin, Zaherawati, Noordin, Mohd Yusof, Yaacob dan Ayob (2012) ke atas pekerja-pekerja pihak berkuasa tempatan di Malaysia yang mendapati kelajuan kenaikan pangkat merupakan ukuran yang paling utama untuk mengukur tahap kepuasan kerja. Kajian mereka mendapati kelajuan kenaikan pangkat di dalam organisasi pihak berkuasa tempatan terlalu perlahan. Pemberian kenaikan pangkat kepada pekerja terlalu terhad dan mengambil masa yang terlalu lama akan menjejaskan kepuasan kerja di kalangan pekerja terhadap organisasi semasa. Ini disebabkan tidak terdapat kekosongan jawatan untuk kenaikan pangkat di dalam organisasi. Ini bermakna kelajuan kenaikan pangkat yang perlahan akan memberi kesan tahap kepuasan kerja. Pernyataan ini juga disokong oleh kajian yang dilaksanakan oleh (Kumazawa, 2010) yang dijalankan ke atas responden di kalangan tentera laut di Amerika Syarikat yang mendapati responden akan membandingkan kelajuan kenaikan pangkat mereka dengan rakan-rakan mereka di jabatan-jabatan lain sama ada mereka dinaikkan pangkat secara cepat ataupun perlahan. Apabila kepuasan kerja menurun, prestasi dan motivasi di kalangan pekerja akan turun sama menurun akibat sumbangan pekerja terhadap organisasi tidak mendapat penghargaan daripada organisasi melalui pemberian kenaikan pangkat mengikut masa yang telah ditetapkan. Kenyataan ini dipersetujui oleh hasil kajian yang diperolehi oleh Weng et. all (2010) motivasi dan prestasi kerja akan menurun apabila pemberian kenaikan pangkat gagal diberikan dalam tempoh masa perkhidmatan yang ditetapkan.

Bagi perkhidmatan awam persekutuan di Malaysia, terdapat perbezaan peraturan dan polisi tempoh perkhidmatan atau senioriti seseorang penjawat awam ditetapkan sebelum pemberian kenaikan pangkat dipertimbangkan oleh lembaga kenaikan pangkat di setiap jabatan dan agensi persekutuan. Peraturan dan polisi tempoh perkhidmatan dan senioriti seseorang penjawat awam persekutuan sebelum kenaikan pangkat dipertimbangkan terkandung di dalam fasal (d) Peraturan Perlantikan, Kenaikan Pangkat dan Penamatan Perkhidmatan 2005 [P.U. (A) 176/2005] yang memberi kuasa kepada lembaga kenaikan pangkat di setiap jabatan dan agensi untuk menentukan tempoh perkhidmatan dan senioriti penjawat awam sebelum dipertimbangkan kenaikan pangkat. Ini bermakna skim-skim perkhidmatan yang terdapat di dalam perkhidmatan awam mempunyai perbezaaan bergantung kepada peraturan dan polisi yang ditetapkan oleh lembaga kenaikan pangkat yang terdapat di setiap jabatan adan agensi persekutuan di Malaysia.Perbezaan ini dapat dilihat untuk jawatan Pegawai Perkhidmatan Pendidikan, Pegawai Farmasi dan Pegawai Perubatan yang telah diberi kelebihan dan keistimewaan struktur laluan kenaikan pangkat yang lebih baik berbanding dengan penjawat awam persekutuan yang lain. Mereka boleh dinaikkan pangkat tanpa menunggu kekosongan jawatan di Jabatan Pelajaran, Sekolah, Klinik dan Hospital Kerajaan (Kementerian Pendidikan Malaysia, 2016 dan Kementerian Kesihatan Malaysia, 2016). Laluan peningkatan kerjaya jawatan Pegawai Perkhidmatan Pendidikan, Pegawai Farmasi dan Pegawai Perubatan yang berkhidmat di Jabatan Pelajaran dan Jabatan Kesihatan menggunakan Time Based Kecemerlangan. Lembaga kenaikan pangkat Kementerian Pendidikan Malaysia dan Kementerian Pelajaran Malaysia telah menetapkan permohonan untuk pertimbangan kenaikan pangkat adalah di antara 2 tahun hingga 5 tahun mengikut setiap gred yang telah tetapkan. Kajian ini akan meninjau sama ada perbezaan tempoh masa perkhidmatan, fungsi pekerjaan dan tahap pekerjaan bagi setiap skim perkhidmatan yang terdapat di dalam perkhidmatan awam Malaysia sebelum dipertimbangkan pemberian kenaikan pangkat akan menjejaskan tahap kepuasan kerja atau sebaliknya.

\section{Kepuasan Kerja}

Kajian awal mengenai kepuasan kerja lebih cenderung diberi tumpuan kepada teori-teori yang dikemukakan oleh (Maslow, 1943) heirarki keperluan, sistem nilai (Trompenaars, 1993) dan nilai dimensi (Hofstede 1980, 1989). Judge, Bono, Thoresen, dan Patton (2001) berpendapat bahawa kajian terhadap kepuasan kerja telah banyak dihasilkan di dalam dunia penyelidikan pada masa kini. Namun kajian yang berterusan terhadap kepuasan kerja masih penting. Ini adalah disebabkan faktor dan isu persekitaran PSM yang sentiasa berubah ubah. Menurut Spector, (1997) kepuasan kerja bermaksud sejauh mana individu itu suka terhadap pekerjaan mereka. Kepuasan kerja juga ditakrifkan sebagai satu keadaan keseronokan emosi yang terhasil daripada penilaian pekerja terhadap pekerjaan mereka (Locke, 1969) dan kepuasan kerja seseorang pekerja itu tercapai apabila semua aspek di dalam kerjaya mereka telah tercapai (Dries et. all, 2008).

Walaupun kajian mengenai kepuasan kerja telah banyak dilaksanakan namun para penyelidik masa kini masih tertarik untuk terus membuat kajian. Ini adalah disebabkan kepentingan utamanya untuk kejayaan organisasi (Herzberg, 2003). Kepuasan kerja telah mencetuskan banyak faedah penyelidikan kerana ia memberi kesan terhadap dasar dan amalan PSM (Van Scotter, 2000) yang dilaksanakan di dalam organisasi. Kajian meta-analisis yang dijalankan oleh Judge et. all (2001) berpendapat kepuasan kerja berhubung kait dengan prestasi kerja. Secara khususnya, prestasi yang lebih baik adalah disebabkan oleh kepuasan kerja. Kepentingan kajian terhadap kepuasan kerja muncul hasil dari dua penemuan iaitu: kepuasan kerja yang positif dan kepuasan kerja negatif. Oleh yang demikian, skop kajian ini akan menilai sama ada dasar dan amalan PSM khususnya pengurusan sistem kenaikan pangkat di sektor awam Malaysia pada masa kini menzahirkan kepuasan kerja yang positif atau negatif. Kepuasan kerja yang positif bermakna pekerja berpuas hati dengan 
pengurusan sistem kenaikan pangkat yang diamalkan oleh organisasi. Manakala, kepuasan kerja yang negatif bermakna pekerja tidak berpuas hati dengan sistem kenaikan pangkat sedia ada di amalkan oleh organisasi. Ini juga bermaksud sistem kenaikan pangkat yang tidak memuas hati pekerja perlu dikemaskini agar sesuai dengan persekitaran dasar dan amalan PSM yang terkini terutamanya di sektor awam.

Kajian-kajian lepas menunjukkan kajian mengenai dasar dan amalan PSM dengan kepuasan kerja banyak dilaksanakan ke atas organisasi swasta dan terlalu sedikit kajian yang dilaksanakan ke atas organisasi di sektor awam (Pearson dan Chong, 1997; Yuan, 1997; Miao, Newman, Sun dan Xu 2013; Nouri dan Parker, 2013). Kenyataan ini disokong oleh penyelidik terdahulu di bidang pentadbiran awam dan PSM (Matthews dan Shulman, 2005; Llorens dan Battaglio, 2010) yang bersetuju terdapat keperluan yang mendesak untuk lebih banyak kajian empirikal mengenai dasar dan amalan PSM dan kepuasan kerja perlu dijalankan terutamanya di dalam organisasi sektor awam. Ini adalah disebabkan faktor dan isu persekitaran PSM yang selalu berubah ubah dan seterusnya mempengaruhi ukuran tahap kepuasan kerja di dalam organisasi.

\subsection{METODOLOGI KAJIAN}

Reka bentuk kajian yang dilaksanakan ini merupakan kajian kes untuk menyelidik perlaksanaan amalan sistem kenaikan pangkat dan kesannya terhadap tahap kepuasan kerja di kalangan penjawat awam persekutuan di Malaysia. Oleh yang demikian, populasi kajian ini dijalankan ke atas pegawai-pegawai yang berkhidmat di pelbagai jabatan kerajaan dan badan berkanun persekutuan yang terdapat di Negeri Sabah. Responden dan sampel kajian ini terdiri daripada pegawai yang berada di dalam kumpulan pengurusan dan profesional dari gred 41 sehingga gred 54 serta mempunyai sekurang-kurangnya lima tahun pengalaman kerja di pelbagai jabatan kerajaan dan badan berkanun persekutuan di Sabah. Pegawai kumpulan pengurusan dan profesional merupakan pegawai-pegawai awam yang mempunyai kelayakan akademik serta kepakaran yang pelbagai dan khusus di dalam jawatan yang disandang. Cooke dan Saini (2010) berpendapat penilaian pandangan para pekerja di dalam pelbagai peringkat jawatan boleh membantu penyelidik untuk menilai kekuatan dan kelemahan dasar dan amalan PSM di dalam organisasi. Penentuan jumlah sampel kajian ini menggunakan teknik yang disarankan oleh Sekaran (2011). Sekaran (2011) mencadangkan sekiranya jumlah populasi kajian seramai 20,000 orang, jumlah sampel yang dicadangkan adalah 377 orang. Sekiranya jumlah populasi berjumlah 30,000 orang, jumlah sampel kajian yang dicadangkan adalah 379 orang. Jumlah populasi kajian ini adalah seramai 26,707 orang. Oleh yang demikian, jumlah sampel kajian ini seharusnya di antara 377 orang hingga 379 orang ((jadual 1 menunjukkan bilangan keseluruhan penjawat awam persekutuan pelbagai skim perkhidmatan gred 41 hingga gred 54 di jabatan dan badan berkanun persekutuan negeri Sabah)).

Jadual 1 Bilangan keseluruhan penjawat awam persekutuan pelbagai skim perkhidmatan gred 41 hingga gred 54 di jabatan dan badan berkanun persekutuan Negeri Sabah

\begin{tabular}{lll}
\hline Organisasi & \multicolumn{1}{c}{ Gred Jawatan 41 hingga 54 } & Jumlah \\
\hline Jabatan-jabatan Persekutuan & 24,774 Orang & 24,774 Orang \\
$\begin{array}{l}\text { Badan-Badan Berkanun } \\
\text { Persekutuan }\end{array}$ & 1,933 Orang & 1,933 Orang \\
Jumlah & & \\
\hline
\end{tabular}

Sumber : Pejabat Setiausaha Persekutuan Sabah, 2015

Intstrumen kajian ini akan menggunakan sepenuhnya borang kaji selidik bagi memperolehi data daripada responden. Set soalansoalan borang kaji selidik yang telah dibangunkan diadaptasi daripada item item soalan yang pernah digunakan penyelidik terdahulu ke atas kajian mereka. Weng et all (2010) telah membangunkan soalan kaji selidik bagi item-item soalan kaji selidik di bawah pembolehubah sistem kenaikan pangkat. Item-item soalan keadilan sistem kenaikan pangkat (3 item) dan kelajuan kenaikan pangkat (3 item) ini pernah digunakan oleh Weng et. all (2010) untuk tujuan kajian kemajuan kerjaya, kepuasan kerja dan komitmen terhadap organisasi di kalangan pekerja di China. Sementara item-item soalan kaji selidik kepuasan kerja yang digunakan di dalam kajian ini menggunakan item-item soalan kaji selidik single rating method yang dibangunkan oleh Spector (1997). Item-item yang terdapat di dalam borang kaji selidik diukur menggunakan 5-Point Likert Scale bermula dari (1) Tidak Setuju hingga (5) Sangat bersetuju.

Kajian ini akan menggunakan teknik purposive sampling bagi menentukan responden yang terlibat di dalam kajian ini. Ini adalah disebabkan sampel kajian ini khusus untuk responden yang berada di gred khusus iaitu gred 41 hingga gred 54. Menurut Sekaran (2011), purposive sampling terdiri daripada responden yang mempunyai maklumat dan ciri-ciri yang telah ditetapkan oleh penyelidik untuk tujuan tertentu di dalam kajian.

Kajian ini juga melaksanakan analisis faktor bagi memperkukuhkan setiap item yang terdapat di dalam setiap pembolehubah, analisa faktor dilaksanakan untuk menilai setiap ítem yang terdapat pada setiap pembolehubah agar dapat diringkaskan tetapi tidak akan menjejaskan pembolehubah berkenaan. Menurut Kumar, Abdul Talib dan Ramayah (2013), analisa faktor diperlukan untuk mengurangkan item yang agak samar dan dalam masa yang sama dapat mengekalkan item yang penting dalam menyokong setiap pembolehubah. Kajian ini menggunakan komponen analisis varimax rotation test dengan berpandukan kepada factor loading dari 0.50 (Kumar et. all, 2013). 
Jadual 2 Analisis faktor-sistem kenaikan pangkat

\begin{tabular}{lll}
\hline Item-item & F1 & F2 \\
\hline Faktor 1: Keadilan Sistem Kenaikan Pangkat & 0.848 \\
$\begin{array}{l}\text { Organisasi saya mempunyai dasar kenaikan pangkat } \\
\text { dalaman yang adil. }\end{array}$ & \\
$\begin{array}{l}\text { Organisasi saya mempunyai peraturan-peraturan } \\
\text { yang sangat adil. }\end{array}$ & 0.824 \\
$\begin{array}{l}\text { Prosedur organisasi saya untuk membuat keputusan } \\
\text { mengenai kenaikan pangkat adalah adil. }\end{array}$ & 0.851 \\
\end{tabular}

\section{Faktor 2: Kelajuan Kenaikan Pangkat}

Kelajuan kenaikan pangkat saya di dalam organisasi

0.807

ini adalah setiap 5 tahun.

Berbanding dengan organisasi sebelumnya,

kedudukan saya sekarang adalah ideal.

0.667

Berbanding dengan rakan-rakan saya,

saya dinaikkan pangkat dengan lebih cepat.

Jadual 2 menunjukkan nilai factor loading di antara 0.667 sehingga 0.851 .

Jadual 3 Analisis faktor-kepuasan kerja

Item-item

Secara keseluruhannya saya berpuas hati dengan kerja saya.

Secara umum, saya suka berkerja disini.

Setelah semua perkara dipertimbangkan, saya berpuashati

dengan kerja saya sekarang

\section{Factor Loading}

0.857

0.884

0.792

Jadual 3 pula menunjukkan nilai factor loading berada di antara 0.792 sehingga 0.857 . Nilai factor loading semua pembolehubah menunjukkan analisis data seterusnya boleh dijalankan.

Jadual 4 Skor kebolehpercayaan semua pembolehubah

\begin{tabular}{lll}
\hline Pembolehubah & Bilangan Item & Cronbach's Alpha \\
\hline Sistem Kenaikan Pangkat : & & 0.854 \\
Keadilan Sistem Kenaikan Pangkat & 3 Item & 0.675 \\
Kelajuan Kenaikan Pangkat & 3 Item & 0.836 \\
Kepuasan Kerja & 3 Item & \\
\hline
\end{tabular}

Menurut Sekaran (2011), sekiranya nilai cronbach's alpha kurang daripada 0.60, skor kebolehpercayaan item-item soalan kaji selidik itu adalah rendah, manakala skor nilai cronbach's alpha di antara 0.60 hingga 0.80 adalah sederhana namun boleh diterima, sekiranya nilai cronbach's alpha melebihi 0.80 adalah tinggi. Jadual 4 skor kebolehpercayaan semua pembolehubah menunjukkan nilai cronbach's alpha kajian ini di antara 0.675 sehingga 0.854 . Oleh yang demikian, nilai cronbach's alpha kajian ini adalah diterima.

Kajian ini menggunakan perisian IBM SPSS versi 23 untuk tujuan analisis data. Kaedah regresi perkalian (multiple regression) digunakan bagi menilai hubungan dan rumusan hasil kajian. Tahap signifikan yang ditetapkan di dalam kajian ini adalah nilai $\mathrm{p}$ hendaklah $* *<0.01$ dan $<0.05$ (Kumar et. all, 2013).

\subsection{HASIL KAJIAN DAN PERBINCANGAN}

Borang soal selidik telah diedarkan sebanyak 700 set kepada responden di setiap jabatan dan badan berkanun persekutuan di seluruh negeri Sabah terdiri daripada responden yang berada di dalam gred 41 hingga gred 54, terdiri daripada pelbagai jantina, skim perkhidmatan, status perkahwinan dan latar belakang akademik yang berbeza. Namun begitu, hanya sejumlah 420 borang soal selidik sahaja telah dikembalikan dan hanya 380 borang kaji selidik yang telah dijawab dengan sempurna dan boleh digunakan untuk tujuan analisis data. Sebanyak 40 
borang soal selidik lagi tidak dijawab dengan lengkap atau tidak dijawab langsung oleh responden. Namun, bilangan 380 borang kaji selidik yang digunakan untuk analisis data menepati saranan sampel kajian yang disarankan oleh Sekaran (2011).

\section{Regresi Perkalian}

Kajian ini menggunakan analisis regresi pelbagai untuk melihat sama ada terdapat hubungan yang signifikan di antara pembolehubah bebas sistem kenaikan pangkat (keadilan sistem kenaikan pangkat dan kelajuan kenaikan pangkat) dengan pembolehubah bersandar (kepuasan kerja).

Hipotesis 1:Terdapat perhubungan yang signifikan di antara sistem kenaikan pangkat dan kepuasan kerja perkhidmatan awam di Malaysia.

H1a: Terdapat perhubungan yang signifikan di antara keadilan sistem kenaikan pangkat dan kepuasan kerja.

Jadual 5 menunjukkkan bahawa keadilan sistem kenaikan pangkat $(\beta=0.167),(\mathrm{p}<0.05)$ mempunyai hubungan yang signifikan dengan kepuasan kerja. Oleh yang demikian, H1a adalah diterima.

H1b: Terdapat perhubungan yang signifikan di antara kelajuan kenaikan pangkat dan kepuasan kerja.

Jadual 5 juga menunjukkkan bahawa kelajuan kenaikan pangkat $(\beta=0.142),(p<0.05)$ mempunyai hubungan yang signifikan dengan kepuasan kerja. Oleh yang demikian, H1b adalah diterima.

Jadual 5 Analisis regresi perkalian sistem kenaikan pangkat dan kepuasan kerja

\begin{tabular}{lllr}
$\begin{array}{l}\text { Pembolehubah } \\
\text { Bersandar }\end{array}$ & $\begin{array}{l}\text { Pembolehubah } \\
\text { Bebas }\end{array}$ & Standard Coeffcient & Significant \\
\hline Kepuasan Kerja & $\begin{array}{l}\text { Sistem Kenaikan Pangkat } \\
\text { Keadilan Sistem Kenaikan } \\
\text { Pangkat }\end{array}$ & 0.167 & $0.03^{*}$ \\
& Kelajuan Kenaikan Pangkat & 0.142 & $0.05^{*}$ \\
& $\mathrm{R}^{2}$ & & \\
Adjust $\mathrm{R}^{2} 0.291 \quad 0.304$ & &
\end{tabular}

Tahap Signifikan: **p<0.01, *p<0.05

Hasil analisis regresi yang dijalankan sub konstruk keadilan sistem kenaikan di bawah pembolehubah bebas sistem kenaikan pangkat sebagai peramal yang paling kuat kepuasan kerja. Ini menunjukkan prinsip keadilan di dalam peluang dan pemberian sistem kenaikan pangkat di dalam organisasi perlu dilaksanakan selaras dengan dasar, polisi dan prosidur yang ditetapkan oleh organisasi. Hasil kajian ini selaras dengan penemuan hasil kajian yang dilaksanakan oleh (Choi, 2011; Erdrogan et. all, 2006; Aryee et all, 2002; Sweeney dan McFarlin, 1993). Kajian-kajian mereka mendapati sistem kenaikan pangkat di dalam organisasi perlu dilaksanakan dengan amalan dan dasar sistem kenaikan pangkat yang telah ditetapkan tanpa ada unsur bias dan berat sebelah. Hasil kajian ini juga selaras dengan teori pertukaran sosial yang mencadangkan pemberian ganjaran dan pengiktirafan perlu dilaksanakan dengan adil dan saksama bagi mempastikan kepuasan kerja tercapai di dalam organisasi.

Perlaksanaan sistem kenaikan pangkat yang tidak adil akan mempunyai kesan yang kuat ke atas tahap kepuasan kerja dalam konteks penjawat awam persekutuan di sektor awam. Hasil kajian ini mendapati penjawat awam terdiri daripada pegawai gred 41 hingga gred 54 berpuashati dengan prinsip keadilan terhadap peluang dan pemberian kenaikan pangkat yang dilaksanakan di dalam organiasi seperti yang terkandung di dalam Peraturan Perlantikan, Kenaikan Pangkat dan Penamatan Perkhidmatan 2005 [P.U. (A) 176/2005] dan Pekeliling Perkhidmatan Bilangan 7 Tahun 2010 bagi Panduan Pengurusan Pemangkuan dan Kenaikan Pangkat untuk Pegawai Perkhidmatan Awam Persekutuan di bawah SSM.

Manakala sub konstruk kelajuan kenaikan pangkat juga didapati mempunyai hubungan yang signifikan dengan kepuasan kerja. Hasil kajian ini selaras dengan dapatan kajian yang diperolehi oleh (O'Donell dan Sheilds, 2002; Aminudin et. all, 2012). Hasil kajian ini menunjukkan penjawat sektor awam berpuas hati dengan pekerjaan mereka. Kelajuan pemberian kenaikan pangkat yang diberikan oleh organisasi masing-masing didapati mengikut tempoh masa perkhidmatan dan senioriti di kalangan penjawat awam persekutuan di Malaysia. Ini juga menunjukkan lembaga kenaikan pangkat organisasi telah menjalankan tugasnya dengan baik berpandukan Peraturan Perlantikan, Kenaikan Pangkat dan Penamatan Perkhidmatan 2005 [P.U. (A) 176/2005] dan Pekeliling Perkhidmatan Bilangan 7 Tahun 2010 bagi Panduan Pengurusan Pemangkuan dan Kenaikan Pangkat untuk Pegawai Perkhidmatan Awam Persekutuan di bawah SSM. Ini juga bermaksud kenyataan akhbar yang di utarakan oleh Ketua Setiausaha Negara bahawa kenaikan pangkat sebilangan skim-skim perkhidmatan yang terdapat di dalam perkhidmatan awam begitu perlahan adalah tidak benar. Penjawat awam berpuas hati dengan sistem kenaikan pangkat yang di amalkan oleh organisasi pada masa kini.

\subsection{KESIMPULAN}

Kajian ini merupakan kajian kes yang dijalankan bertujuan untuk meneroka hubungan sistem kenaikan pangkat dengan tahap kepuasan kerja di kalangan penjawat awam persekutuan di Malysia. Hasil kajian menunjukkan penjawat awam persekutuan di Malaysia berpuas hati dengan urusan pemberian kenaikan pangkat yang dilaksanakan di dalam organisasi masing-masing. Kenaikan pangkat secara khusus 
merupakan laluan peningkatan kerjaya di dalam organisasi. Kenaikan pangkat juga merupakan satu anugerah, ganjaran dan pengiktirafan yang diberikan organisasi terhadap pekerja yang telah menunjukkan kerja dengan baik di dalam satu tempoh perkhidmatan di dalam organisasi.

Bagi mengekalkan tahap kepuasan kerja di kalangan penjawat persekutuan kekal pada masa akan datang, kajian ini mencadangkan agar tempoh perkhidmatan untuk pertimbangan kenaikan pangkat perlu diubahsuai agar sesuai dengan persekitaran dan cabaran PSM pada masa akan datang agar dapat menghindarkan penjawat awam tidak berpuas hati dengan organisasi akibat pemberian kenaikan pangkat yang terlalu lama pada masa akan datang. Tempoh yang paling ideal adalah di antara 5 hingga 8 tahun tempoh perkhidmatan bagi melayakkan penjawat awam persekutuan memohon kenaikan pangkat di dalam organisasi. Ini bagi membolehkan pekerja lebih bermotivasi bekerja dengan penuh prestasi dan menyediakan mereka mempelajari secara mendalam visi, misi dan objektif organisasi sebelum dinaikkan pangkat. Oleh yang demikian, kajian ini mencadangkan tempoh perkhidmatan bagi maksud pertimbangan kenaikan pangkat kepada penjawat awam persekutuan perlu dilaksanakan sebagai satu dasar dan polisi pada masa akan datang. Jabatan Perkhidmatan Awam telah melaksanakan dasar dan amalan ini terhadap profession pegawai perubatan, pegawai farmasi dan pegawai perkhidmatan pendidikan. Seharusnya dasar dan amalan ini dipanjangkan untuk semua penjawat awam persekutuan di Malaysia pada masa akan datang.

Kajian ini telah dijalankan ke atas responden penjawat awam persekutuan di sektor awam Malaysia yang bertugas di negeri Sabah. Kajian ini mencadangkan agar kajian pada masa akan datang dapat dilaksanakan ke atas penjawat awam di sektor awam negeri dan pihak berkuasa tempatan. Walaubagaimanapun kajian ini telah menyumbang tinjauan literatur di bidang PSM dengan meluaskan sumbangan bukti kajian empirikal bidang PSM di sektor awam Malaysia. Dapatan kajian ini juga telah menyumbang penambahbaikan urusan penambahbaikan urusan kenaikan pangkat di sektor awam bagi mempastikan kepuasan kerja di kalangan penjawat awam persekutuan di Malaysia dalam keadaan yang memuaskan. Pekerja yang berpuashati dengan pekerjaannya akan meningkatkan potensi dan prestasi diri masing-masing dan seterusnya penyampaian perkhidmatan kepada rakyat dalam tahap yang memuaskan.

\section{Rujukan}

Aminudin. A, Zaherawati. Z, Noordin. N, Mohd Yusof A.Z, Yaacob M.A dan Ayob N.Z (2012), Contributory Effects Of HR Practice On Employees Job Satisfaction In Local Government. Asian Jounal of Business and Management Science,.1(8), 53-61.

Aryee, S, Budhwar, PS \& Chen, ZX (2002). Trust as a Mediator Of The Relationship Between Organizational Justice And Work Outcomes: Test Of A Social Exchange Mode. Journal of Organizational Behavior, 23(3), 267-285.

Baker, George, Michael Jensen, and Kevin Murphy (1988), Compensation and Incentives: Practice vs. Theory. Journal of Finance, 43 (1988), 593-616.

Blau, PM (ed.) (1964). Exchange and Power In Social Life, John Wiley \& Sons, New York.

Burnett, MF, Williamson, IO \& Bartol, KM (2009). The moderating Effect Of Personality On Employees' Reactions To Procedural Fairness And Outcome Favorability. Journal of Business and Psychology, 1-16.

Ch'ng, H. K., Chong, W. K., \& Nakeswari (2010). The Satisfaction Level Of Penang Private College Lecturers. International Journal of Trade, Economics and Finance, 1, 168-172.

Choi, S (2011). Organizational Justice And Employee Work Attitudes: The Federal Case. American Review of Public Administration, 41(2), 185-204.

Cooke, FL \& Saini, DS (2010). How Does the HR strategy Support An Innovation Oriented Business Strategy? An Investigation Of Institutional Context And Organizational Practices In Indian Firms. Human Resource Management, 49(3), 377-400.

Danish, R.Q., \& Usman, H. (2010). The Impact Of Reward And Recognition On Job Satisfaction And Motivation: An Empirical Study From Pakistan. International Journal of Business and Management, 5(2), 112-124

Drafke, M.W., and Kossen, S. (2002). The Human Side of Organizations (8 th ed.). New Jersey: Prentice-Hall, Inc.

Dries, N, Pepermans, R \& De Kerpel, E (2008). Exploring Four Generations' Beliefs About Career: Is "Satisfied" The New "Successful"?. Journal of Managerial Psychology, 23(8), 927-928.

Erdrogan, B, Liden, RC \& Kraimer, ML (2006). Justice and Leader-Member Exchange: The Moderating Role Of Organizational Culture. Academy of Management Journal, 49(2), 395-406

Folger, R \& Konovsky, MA (1989). Effects of Procedural And Distributive Justice On Reactions To Pay Raise Decisions. Academy of Management Journal, 32(1), $115-130$.

Heery, E. \& Noon, M. (2001). A Dictionary Of Human Resource Management. New York: Oxford University Press.

Herzberg, F (2003). One More Time: How Do You Motivate Employees?. Harvard Business Review, 81(1), pp. 87-96.

Hofstede, G (1980). Motivation, Leadership, And Organization: Do American Theories Apply Abroad?. Organizational Dynamics, 9(1), 42-63.

Hofstede, G (1989). Organising For Cultural Diversity. European Management Journal, 7(4), 390-397.

Judge, TA, Bono, JE, Thoresen, CJ \& Patton, GK (2001). The Job Satisfaction-Job Performance Relationship: A Qualitative And Quantitative Review. Psychological Bulletin, 127(3), 376-402.

Kementerian Kesihatan Malaysia (2016). Kementerian Kesihatan Malaysia Portal. Kementerian Kesihatan Malaysia dilihat pada 3 Januari 2016, http://www.moh.gov.my/index.php/pages/view/126.

Kementerian Pelajaran Malaysia (2016). Kementerian Pelajaran Malaysia Potral. Kementerian Pelajaran Malaysia dilihat pada 3 Januari 2016, http://www.moe.gov.my/images/Arkib/surat-siaran-iklan-tbbk-ppp-jan-hingga-jun-2017.pdf.

Kumar. M., Abdul Talib. S., T. Ramayah. (2013). Business Research Methods. Oxford University Press.

Kumazawa, R (2010). Promotion Speed And Its Effect On Attrition Of Navy-Enlisted Personnel: Addressing Heterogeneity In High School Credentials. Applied Economics, 42(20), 2563-76.

Kuvaas, B (2003). Employee Ownership And Affective Organizational Commitment: Employees' Perceptions Of Fairness And Their Preference For Company Shares Over Cash. Scandinavian Journal of Management, 19(2), 193-212.

Landy, F.J. (1989). Psychology of Work Behavior (4th ed.). Belmont: Wadsworth.

Larwood, L. (1984). Organisational Behavior and Management. Boston: Kent Publishing Company.

Lazear, E.P., \& Rosen, S. (1981). Rank-Order Tournaments As Optimum Labor Contracts. Journal of Political Economy, 89, 841-864.

Llorens, JJ \& Battaglio, RP (2010). Human Resources Management In A Changing World: Reassessing Public Human Resources Management Education. Review of Public Personnel Administration, 30(1), 112-32.

Locke, EA (1969). What is Job Satisfaction?, Organizational Behavior and Human Performance, 4(4), 309-36.

Maimunah. A (2009). Human Resourse Management, Oxford Revision Series, Malaysia.

Matthews, J \& Shulman, AD (2005). Competitive Advantage In Public-Sector Organizations: Explaining The Public Good/Sustainable Competitive Advantage Paradox. Journal of Business Research, 58(2), 232-40.

Miao, Q, Newman, A, Sun, Y \& Xu, L (2013). What Factors Influence The Organizational Commitment Of Public Sector Employees In China? The Role Of Extrinsic, Intrinsic And Social Rewards. The International Journal of Human Resource Management, 24(17), 3262-80. 
Nouri, H \& Parker, RJ (2013). Career Growth Opportunities And Employee Turnover Intentions In Public Accounting Firms. British Accounting Review, 45(2), 13848

O’Donnell, M \& Shields, J (2002). Performanc in the Australian Federal Public Sector. Journal of Industrial Relations, 44(3), $435-57$.

Pearson, CAL \& Chong, J (1997). Contributions of Job Content And Social Information On Organizational Commitment And Job Satisfaction: An Exploration In A Malaysian Nursing Context. Journal of Occupational and Organizational Psychology, 70(4), 357-74.

Pejabat Setiausaha Persekutuan Sabah (2015), Data Perjawatan Pegawai dan Kakitangan Persekutuan Negeri Sabah.

Pekeliling Perkhidmatan Bilangan 7 Tahun 2010 bagi Panduan Pengurusan Pemangkuan dan Kenaikan Pangkat untuk Pegawai Perkhidmatan Awam Persekutuan di bawah Sistem Saraan Baru (SSM)

Peraturan Perlantikan, Kenaikan Pangkat dan Penamatan Perkhidmatan 2005 (Jabatan Perkhidmatan Awam) [P.U. (A) 176/2005].

Rosen, CC, Slater, DJ, Chang, C-H \& Johnson, RE (2013). Let's and Validation Of The Ex Post I-Deals Scale. Journal of Management, 39(3), 709-42.

Salamin, A., \& Hom, P. W. (2005). In Search Of The Elusive U-Shaped Performance-Turnover Relationship: Are High Performing Swiss Bankers More Liable To Quit? Journal of Applied Psychology, 90, 1204-1216.

Sekaran. U (2011). Research Methods For Business. A Skill Building Approach 4th'. Willy India Edition.

Seketariat Komanwel (ed.) 2004, A Profile Of The Public Service Of Malaysia: Current Good Practices And New Developments In Public Service Management, Commonwealth Secretariat, London.

Sinar Harian (30 April 2013), Kenaikan Pangkat Gred Jawatan Kakitangan Awam Dalam Skim Perkhidmatan Tertutup Di Jabatan-Jabatan Kerajaan Agak Perlahan Berbanding Dengan Mereka Di Dalam Skim Perkhidmatan Terbuka. (http://www.sinarharian.com.my/ali-hamsa-kerajaan-pertimbang-time-based promotion-di-jabatan-tertutup-1.155635).

Spector, PE (ed.) (1997). Job Satisfaction: Application Assessment, Cause And Consequences, Sage Publications, London.

Sweeney, PD \& McFarlin, DB (1993). The Workers' Ends And The Means: Evaluatian Examination Of Four Models Of Distributive And Procedural Justice. Organizational Behavior and Human Decision Processes, 55(1), 23-40.

Trompenaars, F (ed.) (1993). Riding the Waves Of Culture: Understanding Cultural Diversity In Business, The Economist Books, London: Brealey.

Van Scotter, JR (2000).Relationships of Task Performance And Contextual Performance With Turnover, Job Satisfaction, And Affective Commitment. Human Resource Management Review, 10(1), 79-95.

Weng, Q. X., McElroy, J. C., Morrow, P. C., \& Liu, R. (2010). The Relationship Between Career Growth And Organizational Commitment. Journal of Vocational Behavior, 77(3), 391-400.

Wu, P-C \& Chaturvedi, S (2009). The Role Of Procedural Justice And Power Distance In The Relationship Between High Performance Work Systems And Employee Attitudes: A Multilevel Perspective. Journal of Management, 35(5), 1228-47.

Yuan, T (1997). Determinants Of Job Satisfaction Of Federal Government Employees. Public Personnel Management, $26(3), 2$. 